\title{
WestVirginiaUniversity
}

THE RESEARCH REPOSITORY @ WVU

Graduate Theses, Dissertations, and Problem Reports

2000

\section{Synthesis and characterization of metal oxide nanoparticles}

\author{
Heidi Jo Magnone \\ West Virginia University
}

Follow this and additional works at: https://researchrepository.wvu.edu/etd

\section{Recommended Citation}

Magnone, Heidi Jo, "Synthesis and characterization of metal oxide nanoparticles" (2000). Graduate Theses, Dissertations, and Problem Reports. 1129.

https://researchrepository.wvu.edu/etd/1129

This Thesis is protected by copyright and/or related rights. It has been brought to you by the The Research Repository @ WVU with permission from the rights-holder(s). You are free to use this Thesis in any way that is permitted by the copyright and related rights legislation that applies to your use. For other uses you must obtain permission from the rights-holder(s) directly, unless additional rights are indicated by a Creative Commons license in the record and/ or on the work itself. This Thesis has been accepted for inclusion in WVU Graduate Theses, Dissertations, and Problem Reports collection by an authorized administrator of The Research Repository @ WVU. For more information, please contact researchrepository@mail.wvu.edu. 


\title{
SYNTHESIS AND CHARACTERIZATION OF METAL OXIDE NANOPARTICLES
}

\author{
Heidi J. Magnone
}

Thesis submitted to the College of Arts and Sciences at West Virginia University in partial fulfillment of the requirements for the degree of

\author{
Master of Science \\ In \\ Physics
}
Dr. Mohindar S. Seehra, Chair
Dr. John E. Littleton
Dr. Wathiq Abdul-Razzaq
Department of Physics
Morgantown, West Virginia
2000

Keywords: Nanoparticle, Synthesis, Sol-Gel, Electrochemical, Copper Oxide, Cobalt Oxide, Manganese Oxide, Nickel Oxide, $\mathrm{CuO}, \mathrm{Co}_{3} \mathrm{O}_{4}, \mathrm{Mn}_{5} \mathrm{O}_{8}, \mathrm{NiO}$ 


\section{ABSTRACT \\ SYNTHESIS AND CHARACTERIZATION OF METAL OXIDE NANOPARTICLES \\ HEIDI MAGNONE}

Nanoparticles of $\mathrm{CuO}, \mathrm{Co}_{3} \mathrm{O}_{4}$ and $\mathrm{Mn}_{5} \mathrm{O}_{8}$ were prepared via sol-gel chemical routes. Thermal treatments of the gels were used to obtain particles of different sizes, as determined by the widths of the Bragg lines in $\mathrm{x}$-ray diffraction. To prepare $\mathrm{CuO}$ nanoparticles, a $\mathrm{Cu}(\mathrm{OH})_{2}$ gel was first produced by reacting copper nitrate with sodium hydroxide, followed by annealing the gel at temperatures between $160^{\circ} \mathrm{C}$ to $1,000^{\circ} \mathrm{C}$ to produce particles in the 6 to $36 \mathrm{~nm}$ range. Nanoparticles of $\mathrm{Co}_{3} \mathrm{O}_{4}$ in the size range of 9 to $45 \mathrm{~nm}$ were prepared in an analogous manner by reacting cobalt nitrate and sodium hydroxide. Similar procedures to produce nanoparticles of $\mathrm{MnO}$ resulted only in the synthesis of $\mathrm{Mn}_{3} \mathrm{O}_{4}$. Annealing $\mathrm{Mn}_{3} \mathrm{O}_{4}$ at $400^{\circ} \mathrm{C}$ for three hours produced nanoscale $\mathrm{Mn}_{5} \mathrm{O}_{8}(14 \mathrm{~nm})$, a difficult-to-prepare oxide. Using an electrochemical route, $30 \mathrm{~nm}$ particles of $\mathrm{NiO}$ were also synthesized. Thermogravimetric measurements were used to identify the thermally-induced phase transformations and x-ray diffraction was used to identify the phases and determine the average particle sizes of the phases. 


\section{ACKNOWLEDGEMENTS}

I would like to express my sincere appreciation to my research advisor Dr. Mohindar S. Seehra for his patience, guidance and instruction, and for the valuable research opportunities that he provided for me. I also thank Alex Punnoose for his constant encouragement and helpful comments. The financial support provided by the U.S. Department of Energy (Contract \#DE-FC26-99FT40540) to this research project is also acknowledged. 


\section{TABLE OF CONTENTS}

Abstract

Page

Abstract

ii

$\begin{array}{ll}\text { Acknowledgments } & \text { iii }\end{array}$

Table of Contents $\quad$ iv

List of Figures $\quad$ vi

I. Introduction 1

II. Fundamentals of Sol-Gel Processing 2

2.1 Reaction of Chemical Precursors 4

$\begin{array}{ll}2.2 \text { Gelation } & 10\end{array}$

$\begin{array}{lll}2.3 & \text { Drying } & 13\end{array}$

$\begin{array}{lll}2.4 & \text { Annealing } & 14\end{array}$

III. Sol-Gel Preparation of $\mathrm{CuO}, \mathrm{Co}_{3} \mathrm{O}_{4}$ and $\mathrm{Mn}_{5} \mathrm{O}_{8}$ Nanoparticles 17

$\begin{array}{ll}3.1 & \mathrm{CuO} \text { Nanoparticles } \\ \end{array}$

a. Literature Review 17

b. Synthesis 18

c. Characterization 19

$\begin{array}{lll}3.2 & \mathrm{Co}_{3} \mathrm{O}_{4} \text { Nanoparticles } & 22\end{array}$

a. Literature Review 22

b. Synthesis 23

c. Characterization 23

$\begin{array}{lll}3.1 & \mathrm{Mn}_{5} \mathrm{O}_{8} \text { Nanoparticles } & 26\end{array}$

a. Literature Review 26

b. Synthesis 26

c. Characterization 27

IV. Fundamentals of Electrochemical Synthesis 30 
V. Electrochemical Preparation of NiO Nanoparticles

a. Literature Review 32

b. Synthesis 32

c. Characterization 32

VI. Results and Conclusions 33

$\begin{array}{ll}\text { References } & 35\end{array}$

$\begin{array}{ll}\text { Vita } & 38\end{array}$ 


\section{LIST OF FIGURES}

Figure $\quad$ Page

2.1 The Sol-Gel Route 3

2.2 Critical Radius of Nucleation 5

$2.3 \quad$ Electrostatic Double-Layer Repulsion 8

2.4 Potential Energy Between Two Particles 10

2.5 Lateral vs. Linear Linkage of Particles 11

2.6 Neck Formation 12

3.1 X-Ray Diffraction Pattern for $\mathrm{CuO} \quad 20$

3.2 $\mathrm{CuO}$ Particle Size vs. Annealing Temperature 21

3.3 Thermogravimetric Analysis of $\mathrm{Cu}(\mathrm{OH})_{2} \quad 22$

3.4 X-Ray Diffraction Pattern for $\mathrm{Co}_{3} \mathrm{O}_{4} \quad 24$

3.5 $\quad \mathrm{Co}_{3} \mathrm{O}_{4}$ Particle Size vs. Annealing Temperature 24

3.6 Thermogravimetric Analysis of $\mathrm{Co}(\mathrm{OH})_{2} \quad 26$

3.7 X-Ray Diffraction Pattern for $\mathrm{Mn}_{5} \mathrm{O}_{8} \quad 27$

3.8 Thermogravimetric Analysis of $\mathrm{Mn}_{3} \mathrm{O}_{4} \quad 29$

4.1 Electrochemical Production of NiO Nanoparticles 31

4.2 X-Ray Diffraction Pattern for NiO 33 


\section{INTRODUCTION}

Particles of size range 1-100 $\mathrm{nm}$ are considered nanoscale. ${ }^{1}$ These nanoparticles, and structures and devices comprised of them, display unique mechanical, optical, electrical, and magnetic properties that differ radically from the corresponding bulk material. ${ }^{1}$ Applications of nanostructured materials include catalysts, electrolyte membranes, films, and fibers. Current intense research in nanoparticles has created a great demand for their efficient production.

Nanoparticles can be produced through either chemical or physical means. They can be made physically by ball milling, a process in which coarse particles are ground to nanoscale particles. Disadvantages of ball-milling include the high mechanical energy needed (resulting in strain in the particles) and contamination by the material of which the ball mill is made. In chemical methods, by-products form during reactions but they can generally be removed. Chemical techniques provide the power to mix at the molecular level, allowing for the production of highly homogeneous materials.

Nanoparticles can be synthesized chemically through sol-gel processing, electrochemical methods, ${ }^{2}$ hydrothermal techniques, ${ }^{3}$ and chemical vapor deposition. ${ }^{4}$ This work explores sol-gel and electrochemical synthesis. $\mathrm{CuO}, \mathrm{Co}_{3} \mathrm{O}_{4}$ and $\mathrm{Mn}_{5} \mathrm{O}_{8}$ nanoparticles as small as $6.1,9.4$, and $14.0 \mathrm{~nm}$ respectively were synthesized through sol-gel chemistry using metallic salt precursors. $30 \mathrm{~nm}-\mathrm{NiO}$ particles were obtained through electrochemistry. 


\section{FUNDAMENTALS OF SOL-GEL PROCESSING}

Sol-gel processing is convenient for its simple procedures, requiring little more than standard solution chemistry. The initial aim in the sol-gel technique is to produce a sol, which is a suspension of solid colloidal particles in a liquid. The colloidal particles may or may not have the chemical composition of the desired end-product. The particles, through van der Waals attraction, eventually connect to form a gel, a 3-dimensional solid network having high porosity and high specific surface area. The gel can simply be dried and ground if a nanoscale powder is the aim. The wet sol may be deposited onto a substrate and then allowed to gel if a thin film is desired. The gel may be heated to induce chemical phase changes, or to densify a thin film or ceramic structure.

Sol-gel chemistry is used mainly to produce metal oxides, but production of carbides, nitrides, and sulfides is also possible through this route ${ }^{5}$. Metal oxides can be synthesized directly in the initial chemical reaction, or a metal hydroxide may form which can be heated to yield the oxide.

Metallic salts $\left(\mathrm{M}_{\mathrm{m}} \mathrm{X}_{\mathrm{n}}\right)$, alkoxides $\left(\mathrm{M}(\mathrm{OR})_{\mathrm{n}}\right)$, and, less commonly, organometallics (MR) are used as chemical precursors ( $\mathrm{M}$ is a metal, $\mathrm{X}$ is an anion, $\mathrm{R}$ is an alkyl (carbon) group) in sol-gel processing. ${ }^{5}$ In this work, metal salt precursors are used to produce $\mathrm{CuO}, \mathrm{Co}_{3} \mathrm{O}_{4}$ and $\mathrm{Mn}_{5} \mathrm{O}_{8}$ nanoparticles. Addition of sodium hydroxide to a metal nitrate solution yields a metal hydrous oxide sol, which can be annealed to obtain various phases of oxide. Many metal oxide nanoparticles have been made from metal-salt precursors, including $\mathrm{CuO},{ }^{6} \mathrm{Co}_{3} \mathrm{O}_{4},{ }^{7} \mathrm{NiO},{ }^{8} \mathrm{Fe}_{2} \mathrm{O}_{3},{ }^{9} \mathrm{Fe}_{3} \mathrm{O}_{4},{ }^{10} \mathrm{TiO}_{2},{ }^{11} \mathrm{ZrO}_{2}{ }^{12}$ and $\mathrm{ZnO} .{ }^{13}$ 
The four steps in sol-gel processing are: (1.) Reaction of the appropriate chemical precursors to form colloidal particles; (2.) Aggregation of particles to form a gel; (3.) Drying of the gel; (4.) Heating to induce phase transformations and/or densification (see figure 2.1).

\title{
1. Reaction of Precursors to Form Sol
}

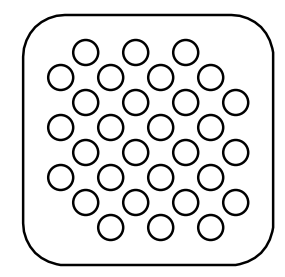

\author{
Colloidal Solid \\ Particles in \\ Liquid
}

\section{Gelation}

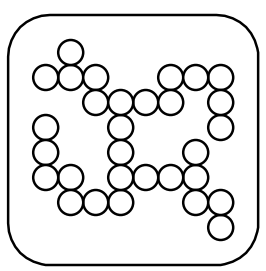
3-Dimensional
Network in
Liquid

\section{Drying}

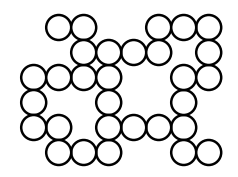

Removal of

Liquid to Obtain

a Xerogel

\section{Annealing}

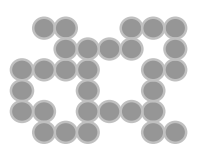

Heating Induces

Phase Transformations

Figure 2.1. The Sol-Gel Route 


\subsection{REACTION OF CHEMICAL PRECURSORS}

For metallic salt precursors, water is an appropriate choice of solvent and it is used exclusively in this work. Various nonaqueous solvent mixtures are also commonly used, depending on the precursors chosen. ${ }^{5}$

When a metal salt, $\mathrm{MX}$, is dissolved in water, a hydrated metal cation, $\mathrm{M}\left(\mathrm{H}_{2} \mathrm{O}\right)_{6}{ }^{\mathrm{z+}}$, is formed where $\mathrm{z}$ is the oxidation number. ${ }^{14}$ Addition of a base gives a hydrolyzed metal complex via the following reaction: ${ }^{5}$

$$
\left[\mathrm{M}\left(\mathrm{H}_{2} \mathrm{O}\right)_{6}\right]^{\mathrm{z}+}+\mathrm{hOH}^{-} \Leftrightarrow\left[\mathrm{M}(\mathrm{OH})_{\mathrm{h}}\left(\mathrm{H}_{2} \mathrm{O}\right)_{6-\mathrm{h}}\right]^{\mathrm{z}-\mathrm{h}}+\mathrm{hH}_{2} \mathrm{O}
$$

When $\mathrm{h}$ is equal to $\mathrm{z}$, the charge of the metal complex is neutralized and the solid hydroxide, $\mathrm{M}(\mathrm{OH})_{\mathrm{z}}\left(\mathrm{H}_{2} \mathrm{O}\right)_{6-\mathrm{z}}$, precipitates. Along with the neutral hydroxide, charged complexes (positive at high $\mathrm{pH}$ and negative at low $\mathrm{pH}$ ) are also expected to form but they are water-soluble and so will not precipitate.

Nucleation and Growth of Particles. Metal hydroxide molecules in the water are drawn to one another through van der Waals forces. With the help of random thermal motion, they come into contact with one another, then bond chemically to form crystals.

The total free energy to form a solid particle of a particular type of material is dependent on the particle size. Assuming for simplicity a spherical particle of radius $r$, the free energy is ${ }^{5}$

$$
\Delta \mathrm{G}_{\mathrm{r}}=\Delta \mathrm{G}_{\mathrm{s}}+\Delta \mathrm{G}_{\mathrm{i}}
$$


where $\Delta \mathrm{G}_{\mathrm{s}}$ is the contribution to the free energy due to the surface, and $\Delta \mathrm{G}_{\mathrm{i}}$ is the contribution due to the phase transformation inside the particle. $\Delta \mathrm{G}_{\mathrm{s}}$ and $\Delta \mathrm{G}_{\mathrm{i}}$ can be expressed as ${ }^{5}$

$$
\begin{aligned}
\Delta \mathrm{G}_{\mathrm{s}} & =4 \pi \mathrm{r}^{2} \Delta \gamma>0 \\
\Delta \mathrm{G}_{\mathrm{i}} & =\left({ }^{4} / 3\right) \pi \mathrm{r}^{3} \Delta \mathrm{G}_{\mathrm{v}}<0
\end{aligned}
$$

where $\Delta \gamma$ is the surface energy and $\Delta \mathrm{G}_{\mathrm{v}}$ is the difference in the free energy per unit volume of the final phase and initial phase. For very small values of $r$, the positive surface contribution is dominant, making $\Delta \mathrm{G}_{\mathrm{r}}$ positive. Because the change in free energy $\Delta \mathrm{G}_{\mathrm{r}}$ must be negative for any process to occur spontaneously, the existence of very small particles (resulting in positive $\Delta \mathrm{G}_{\mathrm{r}}$ ) is thermodynamically unfavorable.

There exists a critical radius, $r_{c}$, such that particles of smaller radius dissolve and those of larger radius grow (see figure 2.2). Despite their thermodynamic instability,

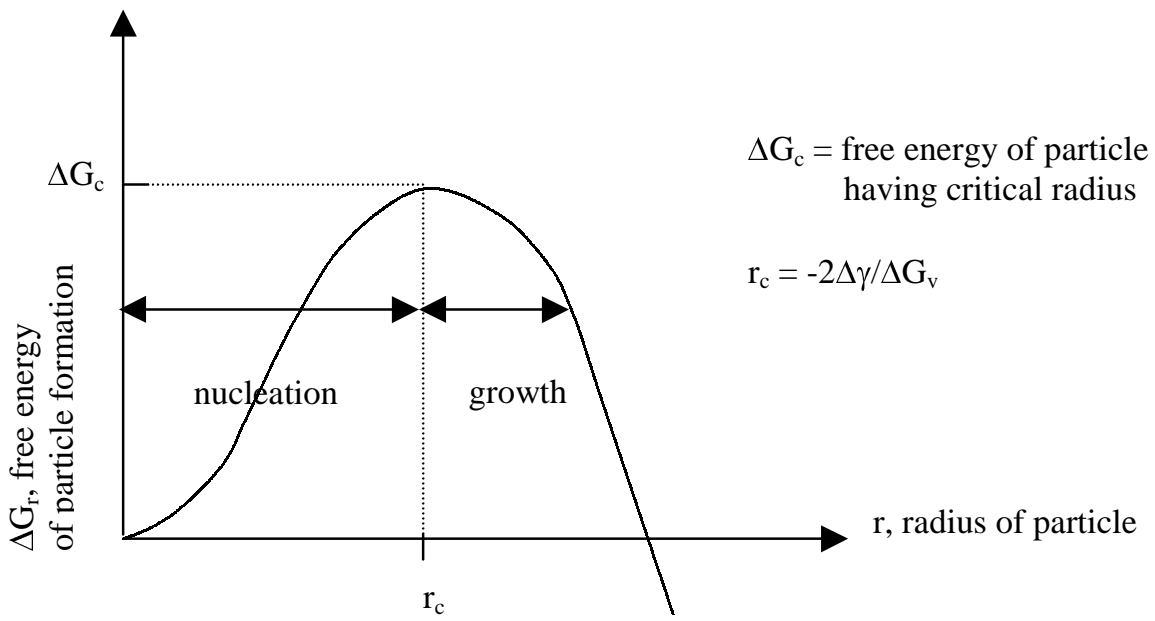

Figure 2.2. Critical Radius of Nucleation 
small particles must form, of course, before they can grow to larger, more stable ones. The continual random thermal motion of solute molecules will cause them to come into contact with one another to form aggregates of subcritical radii. ${ }^{15}$ Most of these aggregates, termed embryos, will dissolve but Brownian motion ensures a finite probability that some will survive long enough to collide with other embryos to form particles of radius $r>r_{c}{ }^{15}$ These particles, called nuclei, are about $1 \mathrm{~nm}$ and will grow by deposition of solute molecules onto their surfaces. ${ }^{5}$ Increase in particle size by nucleusnucleus coagulation becomes increasingly unlikely as nuclei grow-mutual electrostatic repulsion exists between growing nuclei due to surface charges that develop.

The formation of a sol, a suspension of solid colloidal particles in a liquid, is paramount in sol-gel processing. Colloidal particles are of size range $2 \mathrm{~nm}$ to $0.2 \mu \mathrm{m}$, which corresponds to about $10^{3}$ to $10^{9}$ atoms. ${ }^{5}$ Smaller particles have a tendency to redissolve after they form, while larger particles fall out of suspension (hindering gelation) as gravitational forces overcome dispersive forces.

The smallest particles are expected to form from either very high or very low concentrations of reagents. At intermediate concentrations, larger particles form. In dilute solutions, the solute molecules are far apart from one another and from growing nuclei, therefore nuclei grow slowly. Plenty of time is available for new nuclei to form before older nuclei seize all of the available solute molecules for their own growth. This limits the final size achieved by older nuclei. After all molecules have been deposited on particles, growth is halted, leaving older nuclei larger and younger nuclei smaller. The result is a polydisperse sample of small average particle size. 
At high concentrations, the solute molecules are close together so that many nuclei form quickly and almost simultaneously. Most of the solute is initially used up in forming nuclei. Few molecules are left over to support further growth by deposition onto the surfaces of nuclei. A monodisperse sample of small particles is the outcome.

Stability of Particles: The Electrical Double Layer. Metal hydroxide particles, and also metal oxide particles since they generally have surface hydroxyl groups, carry a surface charge dependent upon the specific compound formed and the $\mathrm{pH}$. The surface charge is acquired by adsorption of $\mathrm{H}^{+}$or $\mathrm{OH}^{-}$ions onto the particle surface. In acidic solution, particles gain a positive charge. ${ }^{16}$

$$
\mathrm{M}-\mathrm{OH}+\mathrm{H}^{+} \rightarrow{\mathrm{M}-\mathrm{OH}_{2}^{+}}^{+}
$$

Under basic conditions, particles carry negative charge. ${ }^{16}$

$$
\mathrm{M}-\mathrm{OH}+\mathrm{OH}^{-} \rightarrow{\mathrm{M}-\mathrm{O}^{-}}^{-} \mathrm{H}_{2} \mathrm{O}
$$

The $\mathrm{pH}$ below which the particles are positively charged, and above which are negatively charged, is called the zero point charge, or z.p.c.. The z.p.c., at which the particles are electrically neutral, is a characteristic of the type of material. For hydroxide and oxide compounds, z.p.c.'s vary greatly, ranging anywhere from a pH of 1 to $12 .^{17,18}$

Ions in solution having a charge opposite to that of the particles are termed counterions. In these experiments, metal nitrate precursors are used with an excess of sodium hydroxide so that the particles carry a negative charge and the sodium cations 
take on the role of the counterions. The counterions are drawn toward the particle surface and layer themselves around it. The surface charges with their blanket of counterions comprise what is termed the electrical double layer.

From a distance, the electrical double layer makes particles appear to one another electrically neutral. But at close range, where the double layers may interpenetrate, particles experience mutual electrostatic repulsion. This electrostatic repulsion manifest

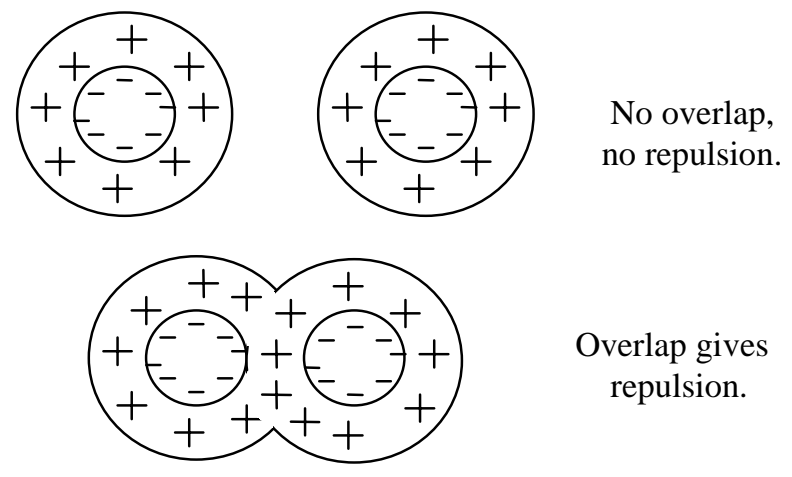

Figure 2.3. Electrostatic Double-Layer Repulsion

at close contact prevents particle coagulation. Colloidal dispersions stabilized by electrical double layers are termed "electrostatic sols," in contrast to "steric sols" which are stabilized by surfactants of large, electrically neutral organic molecules which create a steric, or physical, barrier between particles. (The $\mathrm{NiO}$ particles discussed in sections IV. and V. were stabilized through steric means.) Electrostatic stability is lost at the z.p.c. where no electrical double later exists.

In the presence of an applied electric field, positively charged particles move with the field while negatively charged particles move antiparallel to it. A particle moving in a field will carry along with it many of its counterions and some surrounding fluid. 
Therefore, a shear surface exists between the liquid moving with the particles and the stationary liquid. The electric potential at the shear surface is called the zeta potential, $\zeta$. The isoelectric point, or i.e.p., is the $\mathrm{pH}$ for which $\zeta=0$. At the i.e.p., the electrical mobility is zero, while at the z.p.c. surface charge is zero. Because electrophoretic mobility is often convenient to measure, i.e.p.'s are often reported rather than z.p.c.'s. Values for the i.e.p. and the z.p.c. are close enough to be used interchangeably in practice. They are regarded as equivalent in this work.

The van der Waals attraction between particles (which diminishes as $1 / \mathrm{d}^{6}, \mathrm{~d}$ is the distance between particles) tends to bring them together and promotes coagulation, while the electrical double layer (diminishes as $1 / \mathrm{d}^{2}$ ) tends to keep particles independent. The interplay of van der Waals attraction and electrostatic repulsion between two particles is represented by the curve of figure $2.4{ }^{16}$ The curve for particle distance less than zero is due to repulsion from electron cloud interpenetration. The repulsive barrier prevents particles from achieving close contact and falling into the primary minimum where coagulation is inescapable and specific surface area is irreversibly reduced. When the barrier height is diminished below $\mathrm{kT}$ (the thermal kinetic energy of the particle where $\mathrm{k}$ is the Boltzmann constant and $\mathrm{T}$ is the absolute temperature), as occurs near the z.p.c., particles coagulate. With a barrier of sufficient height, particles will generally eventually settle into the secondary minimum, a process called flocculation. A floc is an aggregate of particles that are connected to one another, yet remain individual entities so that very little reduction in surface area results. Flocculation is often reversible-a little agitation can break up flocs and redisperse the particles. The formation of flocs marks the beginning of gelation. 


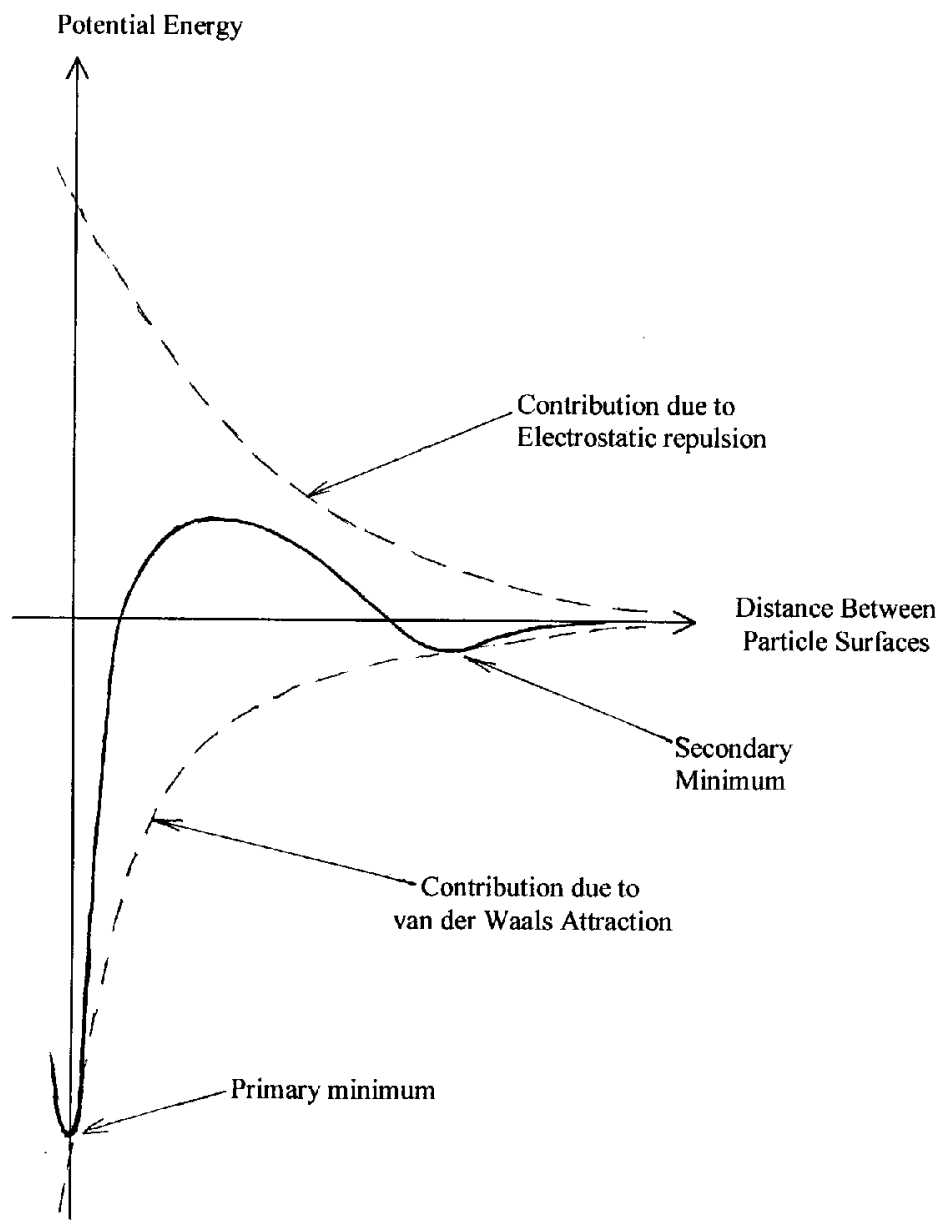

\section{Figure 2.4. Potential Energy Between Two Particles}

\section{$2.2 \quad$ GELATION}

Metal hydroxide suspensions are rarely stable indefinitely. Due to their Brownian motion, particles will make close enough approach to fall into the secondary minimum of figure 2.4 so that flocs are formed. Eventually, floc joins to floc, forming a threedimensional network throughout the liquid. This process, called gelation, is noted by an increase in viscosity of the solid-liquid mix. Gelation allows for the formation of porous, open structures because of the way in which particles preferentially connect. 
When two particles connect, the way in which the electrical double layer configures itself creates greater electrostatic repulsion for lateral linkage than for linear linkage of a third particle. ${ }^{5}$ According to DLVO theory (named after its developers, Derjaguin, Landau, Verwey, and Overbeek), the repulsion for lateral approach is greater than for linear approach by a factor of the order of the square root of $2 .^{5}$ Therefore linear chains of particles develop with occasional lateral bridges connecting them, resulting in open structures of high surface area. Near the z.p.c., where the electrical double layer repulsion is slight, repulsion for lateral approach is so diminished that dense aggregates form and coagulation is imminent (see figure 2.5).

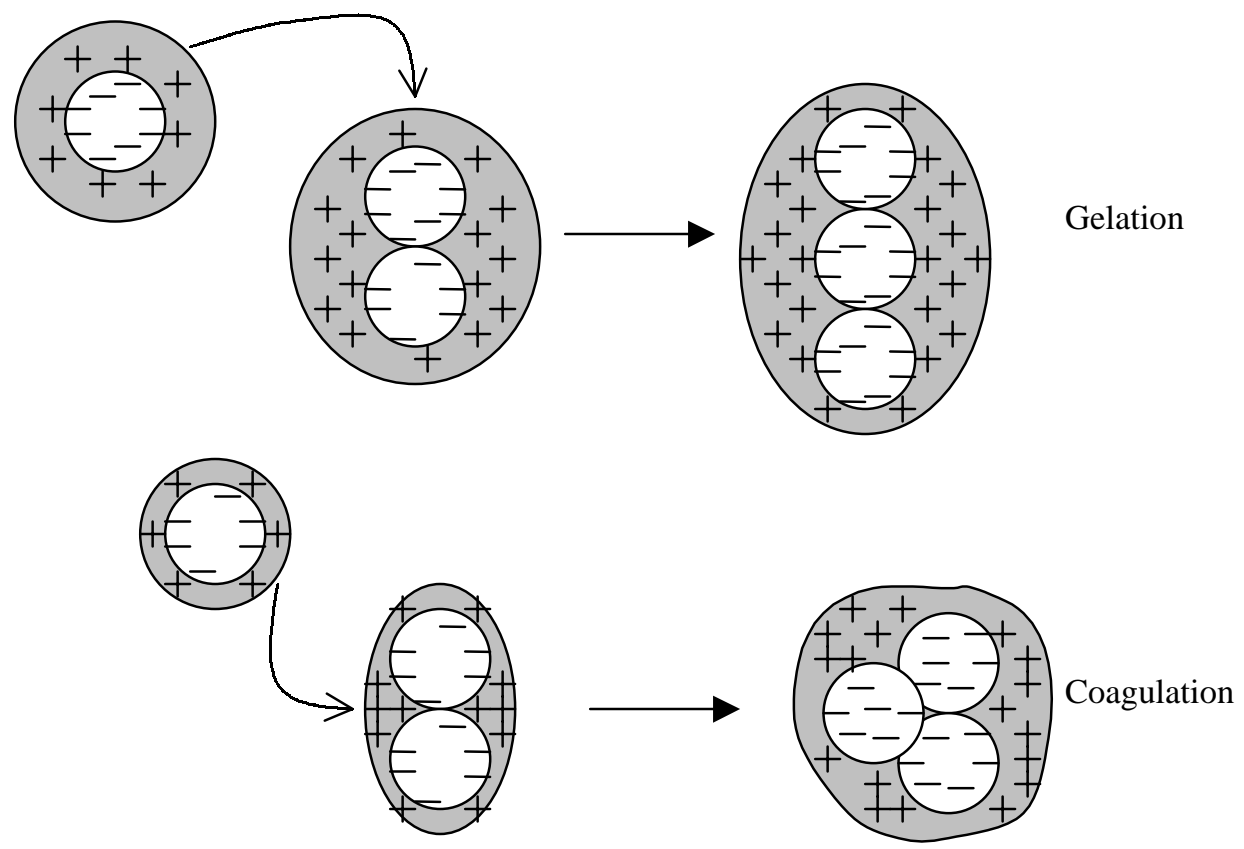

Figure 2.5. Lateral vs. Linear Linkage of Particles

Coarsening of The Gel Structure. The higher the specific surface area of the gel, the less thermodynamically stable it is. Therefore any mechanism available to drive 
down the surface area will operate. For a solid gel network in a liquid, coarsening, also referred to as ripening, causes surface area reduction. ${ }^{16}$

Coarsening is a smoothing of the surfaces of gel pores through dissolution and reprecipitation. The solubility of the surface of a solid is given by ${ }^{16}$

$$
\mathrm{s}=\mathrm{s}_{\mathrm{o}} \exp \left(2 \gamma \mathrm{V}_{\mathrm{m}} / \mathrm{R}_{\mathrm{g}} \mathrm{Tr}\right)
$$

where $s_{o}$ is the solubility of the particular solid material, $\gamma$ is the energy of the solidliquid interface, $\mathrm{V}_{\mathrm{m}}$ is the molar volume of the solid, $\mathrm{R}_{\mathrm{g}}$ is the ideal gas constant, $\mathrm{T}$ is the absolute temperature, and $\mathrm{r}$ is the radius of curvature of the solid. A particle has a positive radius of curvature, while crevices between particles have negative radii, so that solubility is higher on particle surfaces than in crevices. Therefore, there is a tendency for material to dissolve from particle surfaces and then redeposit into crevices. This causes necks to form between particles, reducing the total surface area and stiffening the gel network (see figure 2.6).

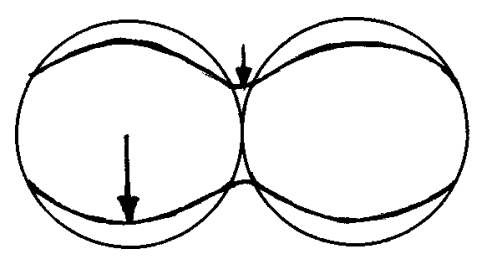

Figure 2.6. Formation of Necks

Washing the gel with water removes water-soluble impurities, but carries away counterions that stabilize particles via the electrical double layer. However, the necks, 
which unfortunately reduce surface area, stabilize the gel by providing the open network with the mechanical strength needed to resist pore collapse.

\subsection{DRYING}

Shrinkage. The capillary forces that develop during the drying stage can cause gels to shrink by a factor of 5 to $10{ }^{16}$ The energy associated with the solid-vapor interface is greater than that of the solid-liquid interface. Therefore, as liquid evaporates from the gel's outer surface, the gel contracts in an effort to avoid exposure of the solid phase to the air. As the gel shrinks, all pores tend to remain saturated with liquid, so that the decrease in gel volume matches the volume of liquid evaporated. ${ }^{16}$

Shrinkage under capillary stresses is possible because the network of the wet gel is very flimsy, with its long strings of particles and huge pores. The strings of particles can bend and additional bridges between them can be built. This restructuring of the network results in denser packing of particles, pore size reduction, and some decrease in surface area (although the surface area of the dry gel is still extremely high, from 100 to 1,000 $\left.\mathrm{m}^{2} / \mathrm{g}\right) .^{5}$ At some point, the particles crowd, making additional rearrangements less likely. The network stiffens, so that the gel becomes strong enough to resist capillary stresses and shrinkage ceases. When the gel can shrink no more, the solid-vapor interface recedes below the gel's outer surface and the pores become unsaturated, containing both liquid and vapor. ${ }^{16}$ The dried gel is a solid unit in its own right, with elastic, shear, and bulk moduli that are not, in general, equivalent to that of the bulk material.

Cracking. The liquid is in tension as it is drawn from the gel's interior to its outer surface. Compressive stresses in the solid act to balance the tension and the gel shrinks. 
The decrease in pore size as the gel shrinks lowers the permeability, making it increasingly difficult to draw out liquid. ${ }^{16}$ Pressure gradients develop such that the tension in the liquid is greater in the exterior regions than in the interior. The surface contracts faster than the inside of the gel, inducing cracking. ${ }^{16}$

Permeability is usually large enough in ordinary ceramics to reduce pressure gradients so that cracking is eliminated, but with gels cracking is difficult to avoid. When the gel is to be used for some application, such as a film or coating, preventing cracking is crucial. Supercritical drying, drying at a critical temperature and pressure eliminating capillary stresses, produces gels which do not shrink or crack. ${ }^{16}$ Gels from supercritical drying are called aerogels, while gels obtained from normal evaporation are called xerogels. Because for these experiments the desired end-products are metal oxide powders, cracking is not a concern and only xerogels are produced.

\subsection{ANNEALING}

Phase Transformations. As the temperature is elevated, a gel passes through various phase transitions until at some high temperature, depending on the nature of the gel but often around $1,000{ }^{\circ} \mathrm{C}$, the most thermodynamically stable state is achieved. ${ }^{5}$ What transition phases appear at specific temperatures is very sensitive to the initial conditions under which the gel was made, such as temperature, $\mathrm{pH}$, and concentrations of reactants. Rare, metastable phases, sometimes difficult to reproduce, have been documented. ${ }^{5}$

Low Temperature Annealing of Metal Hydroxides. As the temperature of a metal hydroxide gel is raised above ambient, the first change noted is loss of water. 
Adsorbed, or residual, water is released first, and then chemical, or structural, water. For example, for +2 metal cations,

$$
\begin{aligned}
& \mathrm{M}(\mathrm{OH})_{2}\left(\mathrm{H}_{2} \mathrm{O}\right) \mathrm{n} \rightarrow \mathrm{M}(\mathrm{OH})_{2}+\mathrm{nH}_{2} \mathrm{O} \text { release of adsorbed water } \\
& \mathrm{M}(\mathrm{OH})_{2} \rightarrow \mathrm{MO}+\mathrm{H}_{2} \mathrm{O} \text { release of chemical water }
\end{aligned}
$$

Release of residual and structural water results in a drop in mass as evidenced by TGA (thermogravimetric analysis). Mass loss of a gel due to water expulsion often occurs at temperatures in the range of $100-300^{\circ} \mathrm{C} .{ }^{5}$ The ratio of adsorbed to structural water usually depends on the chemical recipe used in the gel preparation. ${ }^{5}$

Throughout the expulsion of structural water, and the phase transformation due to release of chemical water, the crystallographic structure remains intact. The gel shrinks as it loses mass, but the phase transformation is topotactic, meaning that a monocrystal of hydroxide remains, roughly, a monocrystal as it transforms to a metal oxide. ${ }^{5}$ At the low temperatures at which water departs, oxygen anions do not have enough thermal energy to move from their lattice positions, making reorganization of oxygen impossible. Very little reduction in surface area occurs during topotactic transformations.

Pore Evolution. Below a critical temperature, which depends on the particular gel, but is generally between 500 and $1,000{ }^{\circ} \mathrm{C}$, the size of the pores remains fairly stable. ${ }^{5}$ In this temperature range, material from particle surfaces is transported through surface atomic diffusion to the necks. The filling in of the necks tends to smooth out pore surfaces, which reduces total surface area, but does not result in changes in pore size. 
Changing pore size requires the movement of atoms within the lattice, which occurs at higher temperatures.

The gradual removal of the porosity through lattice diffusion is a process called sintering, or densification, which results in a large decrease in specific surface area due to changes in pore size and in the number of pores. The specific surface area may decrease by a factor of 10 during the sintering process. ${ }^{5}$ There is the tendency at high temperature, often around $1,000^{\circ} \mathrm{C}$, for lattice atoms to diffuse from larger pores to smaller ones. ${ }^{5}$ Atoms in the vicinity of some point on the surface of a spherical pore are under a tensile mechanical stress, $\sigma,^{5}$

$$
\sigma=-2 \gamma / \mathrm{r}
$$

where $\gamma$ is the pore surface tension and $\mathrm{r}$ is the pore radius. A small radius corresponds to a large stress, so that material is transported through diffusion from larger pores to smaller ones, closing smaller pores and causing larger ones to grow, in order to relieve stress in the system. The result is a decrease in the total number of pores, an increase in average pore size, decrease in specific surface area, and decrease in crystallite size. 


\section{SOL-GEL PREPARATION OF CuO, $\mathrm{Co}_{3} \mathrm{O}_{4} \mathrm{AND} \mathrm{Mn}_{5} \mathrm{O}_{8}$ NANOPARTICLES}

\subsection{CuO NANOPARTICLES}

\section{a. Literature Review}

$\mathrm{CuO}$ nanoparticles have been synthesized from copper (II) acetate using sonochemical techniques ${ }^{19}$ and spin-coating methods. ${ }^{20}$ They have also been produced electrochemically through corrosion of a copper metal anode. ${ }^{21}$ In this work, $\mathrm{CuO}$ nanoparticles were synthesized through a sol-gel chemical route used previously to produce $\mathrm{NiO}$ nanoparticles. ${ }^{8}$ Results of magnetic studies performed on these $\mathrm{CuO}$ samples have been submitted for publication to Physical Review B.

In our experiment, a $0.1 \mathrm{M} \mathrm{Cu}\left(\mathrm{NO}_{3}\right)_{2}$, copper nitrate, aqueous solution was reacted at room temperature with a $1 \mathrm{M} \mathrm{NaOH}$, sodium hydroxide, aqueous solution to obtain a $\mathrm{Cu}(\mathrm{OH})_{2}$, copper (II) hydroxide, suspension. The $\mathrm{Cu}(\mathrm{OH})_{2}$ was filtered, dried, powdered and annealed at temperatures between $160^{\circ} \mathrm{C}$ and $1000^{\circ} \mathrm{C}$ to get $\mathrm{CuO}$ nanoparticles of size range 6.1 to $36 \mathrm{~nm}$. In reviewing the literature it was found that Lee, Her, and Matijevic had also produced $\mathrm{CuO}$ particles of a similar size range from reaction of $\mathrm{Cu}\left(\mathrm{NO}_{3}\right)_{2}$ and $\mathrm{NaOH}$, but their procedure was different. ${ }^{6}$ They performed a reaction of $0.1 \mathrm{M}$ aqueous $\mathrm{Cu}\left(\mathrm{NO}_{3}\right)_{2}$ and $\mathrm{NaOH}$, concentrations in a range of 0.1 to $0.21 \mathrm{M}$, at various temperatures. Their resulting $\mathrm{Cu}(\mathrm{OH})_{2}$ aqueous suspension was aged for a period of time at the reaction temperature to induce conversion to a $\mathrm{CuO}$ aqueous suspension. Then the $\mathrm{CuO}$ particles were separated by centrifugation and dried to obtain a powder. Their 
samples were prepared at reaction temperatures of $20,40,50$, and $90^{\circ} \mathrm{C}$ and were aged for 5 days, 30min, $15 \mathrm{~min}$, and 10min respectively. In another study by Kratohvil and Matijevic, a $\mathrm{Cu}(\mathrm{OH})_{2}$ suspension was dried and powdered, then annealed at $500 \mathrm{C}$ to get $\mathrm{CuO}$ particles which appear from their SEM pictures to be in the micrometer size range. ${ }^{22}$ However, the aim in both of their studies was actually to produce small particles of uniform size and shape rather than to achieve the smallest possible particle size. The exact procedure outlined in this thesis for producing $\mathrm{CuO}$ particles in the lowernanometer range was not found to be documented anywhere in the literature.

\section{b. Synthesis}

Preparation of $\mathrm{Cu}(\mathrm{OH})_{2}$ Gel. $\quad 125 \mathrm{~mL}$ of a $1 \mathrm{M} \mathrm{NaOH}$ aqueous solution was added all at once to $200 \mathrm{~mL}$ of a $0.1 \mathrm{M} \mathrm{Cu}\left(\mathrm{NO}_{3}\right)_{2}$ aqueous solution $(\mathrm{pH}=13)$ to obtain a $\mathrm{Cu}(\mathrm{OH})_{2}$ blue suspension.

$$
\mathrm{Cu}\left(\mathrm{NO}_{3}\right)_{2}+2 \mathrm{NaOH} \rightarrow \mathrm{Cu}(\mathrm{OH})_{2}+2 \mathrm{NaNO}_{2}
$$

The above reaction occurs through deprotonation of the hydrated $\mathrm{Cu}^{2+}$ cation: ${ }^{14}$

$$
\mathrm{Cu}^{2+}\left(\mathrm{H}_{2} \mathrm{O}\right)_{6}+2 \mathrm{OH}^{-} \rightarrow \mathrm{Cu}(\mathrm{OH})_{2}\left(\mathrm{H}_{2} \mathrm{O}\right)_{4}+2 \mathrm{H}_{2} \mathrm{O}
$$

In a $\mathrm{pH}$ of 10 and above, the complexes $\mathrm{Cu}(\mathrm{OH})_{3}{ }^{-}$and $\mathrm{Cu}(\mathrm{OH})_{4}{ }^{2-}$ are also expected to form, ${ }^{14}$ but they are water-soluble and so will not precipitate. The $\mathrm{pH}$ of 13 was far from the i.e.p. of $\mathrm{Cu}(\mathrm{OH})_{2}$, which is $\mathrm{pH}=7.6,{ }^{17}$ to ensure electrostatic stabilization by charged particles. 
Gelation was evident as the $\mathrm{Cu}(\mathrm{OH})_{2}$-plus-water mixture appeared to become more viscous. The gel was separated by filtration, washed with water and filtered. It was then dried in an oven at $50^{\circ} \mathrm{C}$ overnight, over which time it shrunk to approximately onefifth its original size. The product dried to a hard, low-density, blue solid unit. The gel was ground to a powder.

Transformation of $\mathrm{Cu}(\mathrm{OH})_{2}$ to $\mathrm{CuO}$. The copper hydroxide powder was annealed at various temperatures to obtain $\mathrm{CuO}$ nanoparticles.

$$
\mathrm{Cu}(\mathrm{OH})_{2} \rightarrow \mathrm{CuO}+\mathrm{H}_{2} \mathrm{O}
$$

The existence of pure $\mathrm{CuO}$ and the size of the particles were determined by x-ray diffraction (XRD) using a Rigaku D/Max diffractometer.

\section{c. Characterization}

The average particle sizes of the $\mathrm{CuO}$ samples were determined from the $\mathrm{x}$-ray diffraction patterns. Broad peaks correspond to small particles, while large particles are indicated by narrow peaks. The average crystallite dimension, $\mathrm{L}_{\mathrm{hkl}}$, where hkl indicates the Miller indices of the Bragg peak to be analyzed, can be calculated from the Scherrer formula, ${ }^{23}$

$$
\mathrm{L}_{\mathrm{hkl}}=\mathrm{K} \lambda / \beta \cos \theta
$$


where $\mathrm{K}=0.9, \lambda=0.1542 \mathrm{~nm}$ is the wavelength of the $\mathrm{x}$-rays, $\beta$ is the extra width in radians, and $\theta$ is the Bragg angle of the peak. $\beta$ includes a correction that takes into account the instrumental broadening. It is calculated from

$$
\beta^{2}=B^{2}-b^{2}
$$

where B is the full width at half maximum of the chosen Bragg peak for the sample, and $\mathrm{b}$ is the width of a peak near $\theta$ for a standard sample, which for these studies was a $\mathrm{SiO}_{2}$ crystal.

$\mathrm{CuO}$ nanoparticles of sizes $6.1,7.8,8.8,11.6,16.4,25.7,34.5$ and $36.0 \mathrm{~nm}$ were obtained from annealing temperatures of $160,200,250,300,400,600,800$ and $1,000^{\circ} \mathrm{C}$ respectively. XRD detected no other phases (see figure 3.1), which is significant because

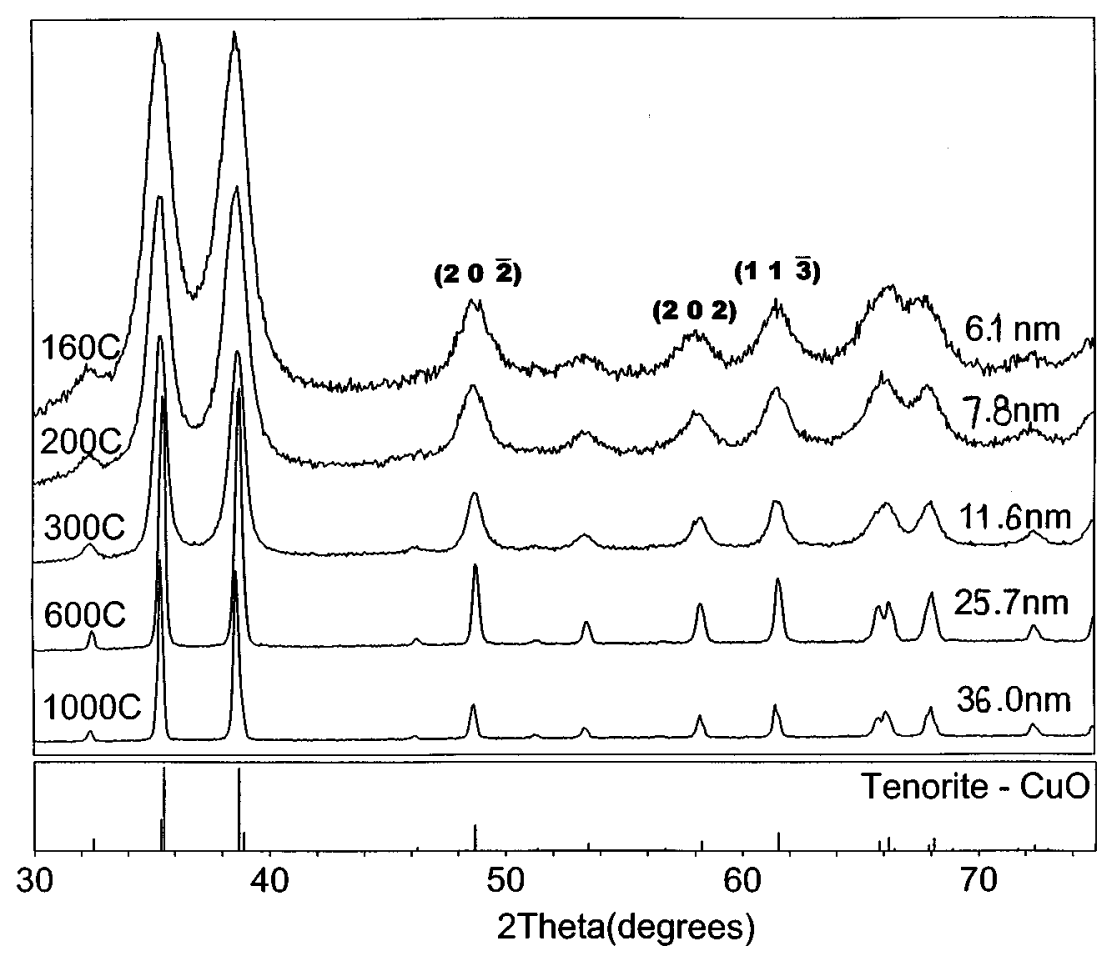

Figure 3.1. $\quad \mathrm{X}$-Ray Diffraction Pattern for $\mathrm{CuO}$ 
Palkar et al have reported that $\mathrm{CuO}$ particles smaller than $25 \mathrm{~nm}$ are unstable, transforming to $\mathrm{Cu}_{2} \mathrm{O} .{ }^{24} \mathrm{CuO}$ particle size was found to increase with increasing annealing temperature (see figure 3.2). The lowest temperature at which the $\mathrm{Cu}(\mathrm{OH})_{2}$ gel converts to $\mathrm{CuO}$ was found to be about $160^{\circ} \mathrm{C}$, and at this temperature the smallest particles of $6.1 \mathrm{~nm}$ formed. TGA (thermogravimetric analysis) confirmed this conversion temperature.

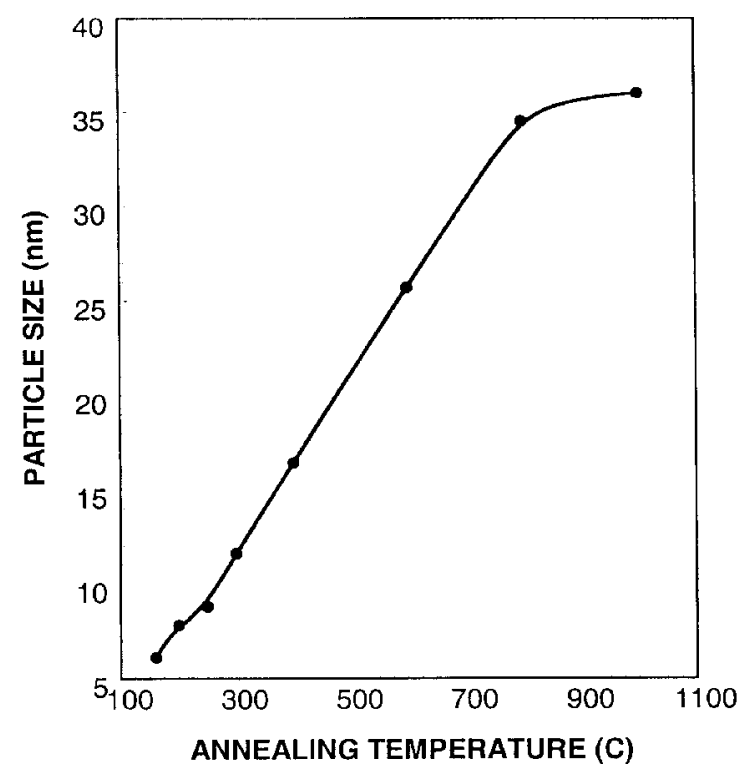

Figure 3.2. CuO Particle Size vs. Annealing Temperature

TGA revealed that $0.77 \mathrm{mg}$ of adsorbed water was released from a $26.6 \mathrm{mg}$ sample of $\mathrm{Cu}(\mathrm{OH})_{2}$ gel as the temperature rose from $25{ }^{\circ} \mathrm{C}$ to about $130{ }^{\circ} \mathrm{C}$, showing that residual water comprised $2.3 \%$ of the original room-temperature gel (see figure 3.3 ).

Over a temperature range of about 130 to $190^{\circ} \mathrm{C}, 4.81 \mathrm{mg}$ of structural water were released as $\mathrm{Cu}(\mathrm{OH})_{2}$ converted to $\mathrm{CuO}$. This shows that the $\mathrm{Cu}(\mathrm{OH})_{2}$ lost $4.81 / 25.83=$ 
$18.6 \%$ of its weight due to chemical water loss, in close agreement with the theoretical value of $18.5 \%$.

(Molecular weight of water/molecular weight of $\left.\mathrm{Cu}(\mathrm{OH})_{2}\right) * 100 \%$

$$
=(18.02 / 97.57) * 100 \%=18.5 \%
$$

The temperature range of conversion to $\mathrm{CuO}$ is in excellent agreement with the range of $140-180^{\circ} \mathrm{C}$ found by Ramamurthy and Secco. ${ }^{25}$

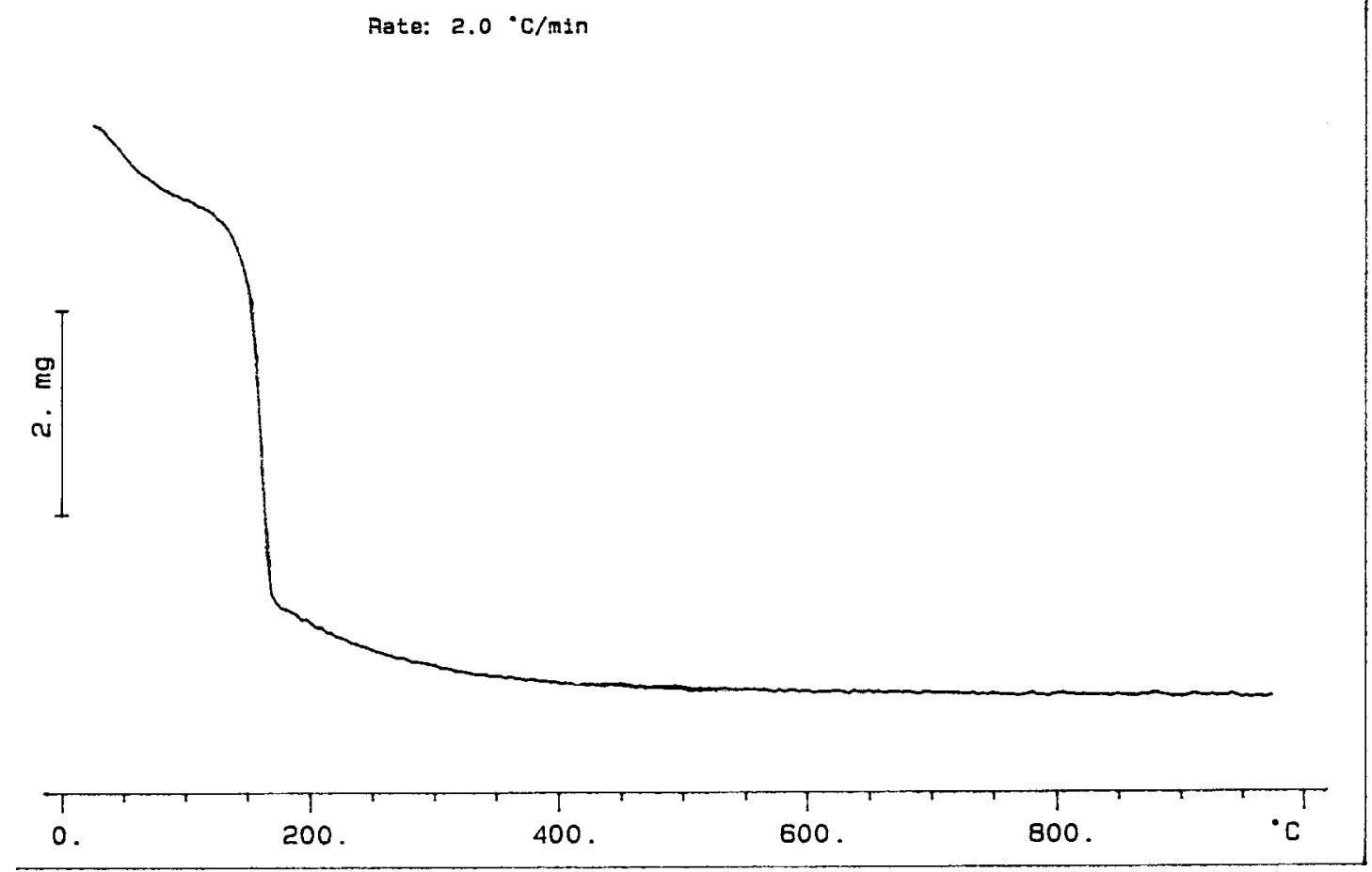

Figure 3.3. Thermogravimetric Analysis of $\mathrm{Cu}(\mathrm{OH})_{2}$

\section{2 $\quad \mathrm{Co}_{3} \mathrm{O}_{4} \mathrm{NANOPARTICLES}$}

\section{a. Literature Review}

$\mathrm{Co}_{3} \mathrm{O}_{4}$ nanoparticles have been synthesized through various chemical techniques.

Aqueous cobalt (II) salt solutions have been heated in the presence of oxygen to obtain a 
nanosized $\mathrm{Co}_{3} \mathrm{O}_{4}$ precipitate. ${ }^{7}$ They have been produced by solid-state oxidation of cobalt metal clusters dispersed in a polymeric matrix ${ }^{26}$. Nanosized $\mathrm{Co}_{3} \mathrm{O}_{4}$ has also been produced from cobalt (II) acetate using a sonochemical method..$^{19}$ In this work, $\mathrm{Co}\left(\mathrm{NO}_{3}\right)_{2}$, cobalt (II) nitrate, was reacted with $\mathrm{NaOH}$ to obtain $\mathrm{Co}(\mathrm{OH})_{2}$, cobalt (II) hydroxide, which upon annealing yielded $\mathrm{Co}_{3} \mathrm{O}_{4}$ particles as small as $9.4 \mathrm{~nm}$. This route to nanostructured $\mathrm{Co}_{3} \mathrm{O}_{4}$ was not found upon surveying the publications.

\section{b. Synthesis}

Preparation of $\mathbf{C o}(\mathbf{O H})_{2}$ Gel. $\quad \mathrm{Co}(\mathrm{OH})_{2}$ gel was prepared in a manner similar to that of the $\mathrm{Cu}(\mathrm{OH})_{2}$ gel. $1 \mathrm{M} \mathrm{NaOH}$ aqueous solution was added quickly to $0.1 \mathrm{M}$ $\mathrm{Co}\left(\mathrm{NO}_{3}\right)_{2}$ aqueous solution to a $\mathrm{pH}$ of 13 (i.e.p. of $\mathrm{Co}(\mathrm{OH})_{2}$ is 11.4$)^{17}$ to obtain the greenish-blue precipitate $\mathrm{Co}(\mathrm{OH})_{2}\left(\mathrm{H}_{2} \mathrm{O}\right)_{4} \cdot{ }^{14}$ The chemical equation and reaction mechanism are analogous to that for $\mathrm{Cu}(\mathrm{OH})_{2}$ formation. ${ }^{14}$ The water-soluble species $\mathrm{Co}(\mathrm{OH})^{3-}\left(\mathrm{H}_{2} \mathrm{O}\right)_{3}$ and $\mathrm{Co}(\mathrm{OH})^{4-}\left(\mathrm{H}_{2} \mathrm{O}\right)_{2}$ are also present at $\mathrm{pH}=13 .{ }^{14}$ The resulting gel was isolated by filtration, washed with distilled water, dried at $50^{\circ} \mathrm{C}$ for 16 hours, then powdered.

Transformation of $\boldsymbol{C o}(\mathrm{OH})_{2}$ to $\mathrm{Co}_{3} \mathrm{O}_{4}$. The $\mathrm{Co}(\mathrm{OH})_{2}$ powder was heated to form $\mathrm{Co}_{3} \mathrm{O}_{4}$ nanoparticles. $\mathrm{CoO}$ particles could not be obtained because of oxidation of cobalt during heating.

\section{c. Characterization}

Existence of pure $\mathrm{Co}_{3} \mathrm{O}_{4}$ was verified by XRD. Particle sizes of 9.4, 11.5, 10.4, $12.4,17.0,42.0$, and $45.5 \mathrm{~nm}$ were obtained from heating at 140, 150, 200, 300, 400, 800, and $950^{\circ} \mathrm{C}$ respectively (see figure 3.4 ). $\mathrm{Co}_{3} \mathrm{O}_{4}$ particle size was found to increase as annealing temperature was increased (see figure 3.5). 
A $20.344 \mathrm{mg}$ sample of $\mathrm{Co}(\mathrm{OH})_{2}$ was analyzed using TGA (see figure 3.6).

$0.9 \mathrm{mg}$, or $4.424 \%$ of the sample weight, was lost in the form of adsorbed water over a temperature range of 25 to $130^{\circ} \mathrm{C}$. When heated above $130^{\circ} \mathrm{C}, \mathrm{Co}(\mathrm{OH})_{2}$ lost $2.725 \mathrm{mg}$ as it converted to $\mathrm{Co}_{3} \mathrm{O}_{4}$. The percent weight loss in this phase transformation is

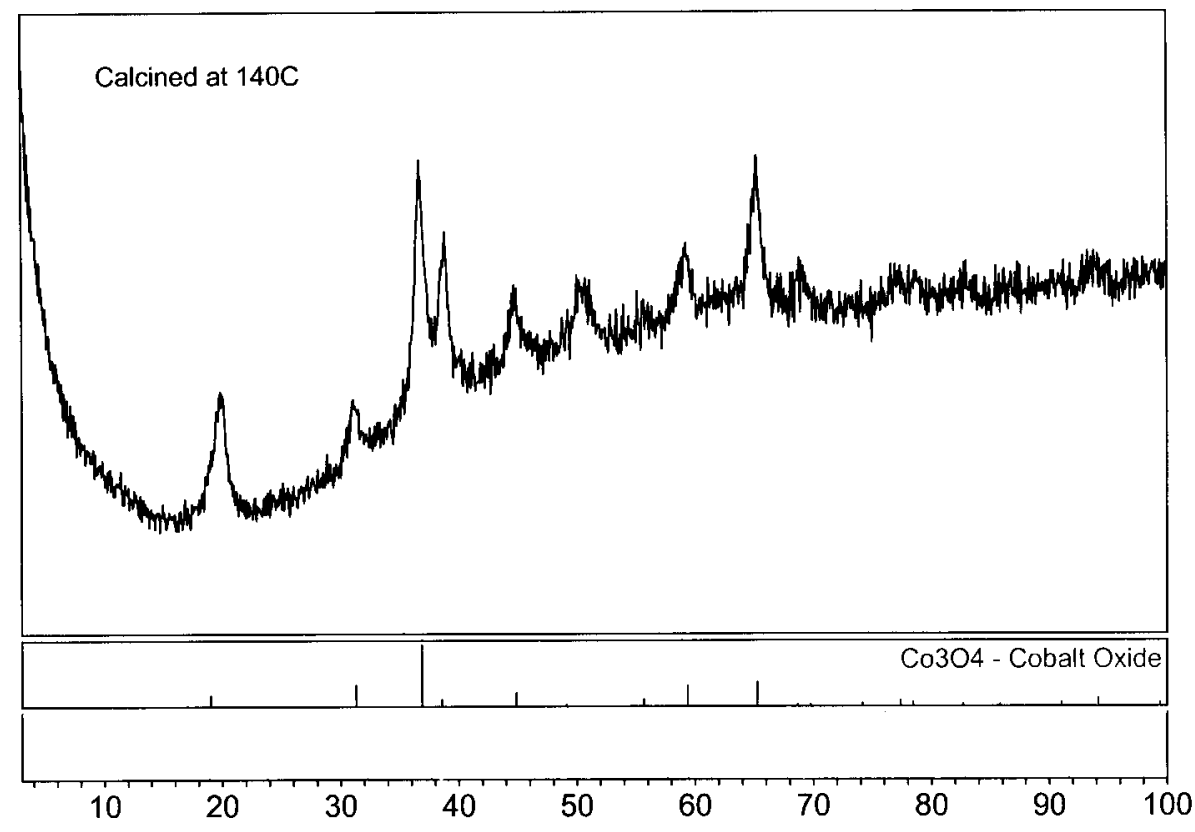

Figure 3.4. X-Ray Diffraction Pattern for $\mathrm{Co}_{3} \mathbf{O}_{4}$ (9.4nm particles) 


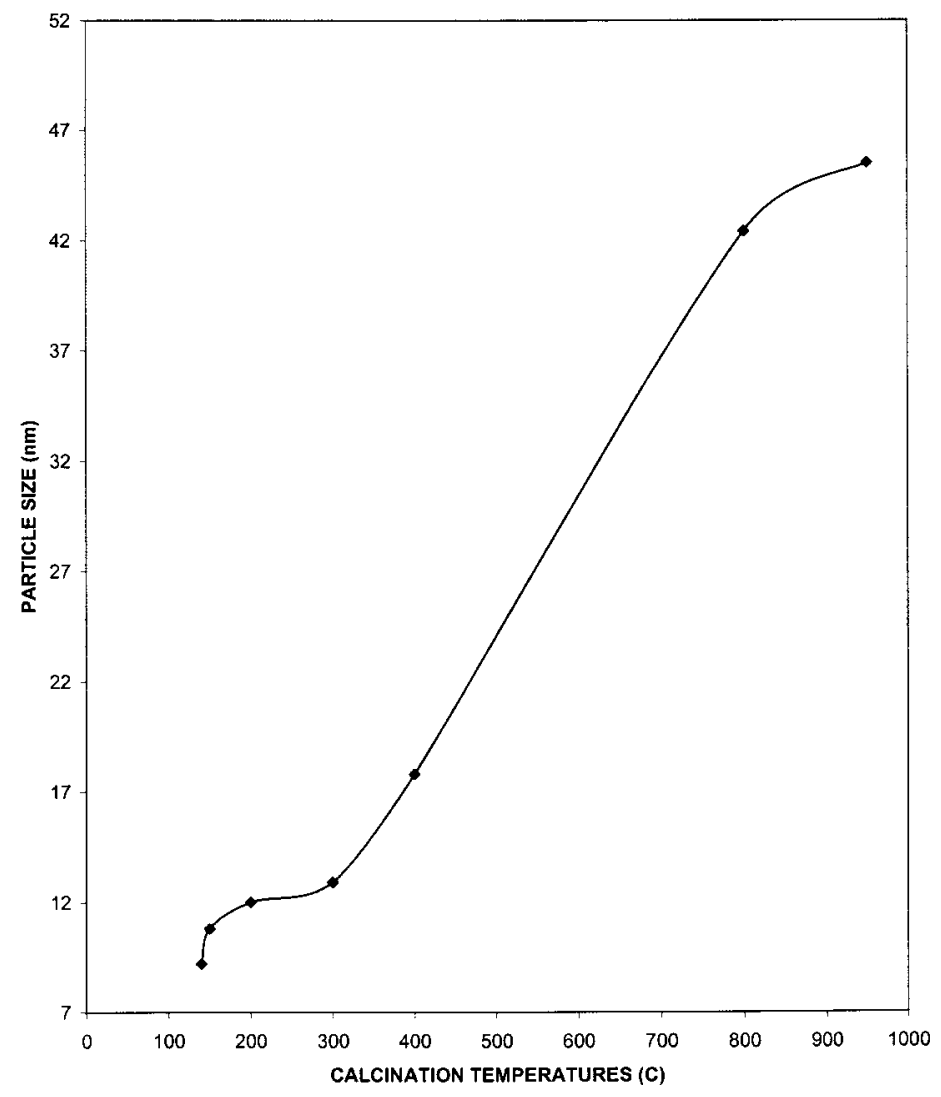

Figure 3.5. $\mathrm{Co}_{3} \mathrm{O}_{4}$ Particle Size vs. Annealing Temperature

$(2.725 / 19.444) * 100 \%=14.0 \%$, in close agreement with the theoretical value of $13.65 \%$. Three formula units of $\mathrm{Co}(\mathrm{OH})_{2}$ lose two water molecules and two hydrogen atoms as it converts to $\mathrm{Co}_{3} \mathrm{O}_{4}$.

$$
3 \mathrm{Co}(\mathrm{OH})_{2} \rightarrow \mathrm{Co}_{3} \mathrm{O}_{4}+2 \mathrm{H}_{2} \mathrm{O}+\mathrm{H}_{2}
$$

Therefore the theoretical weight loss of conversion is

$\left\{\right.$ Molecular weight of $\left.\left(2 \mathrm{H}_{2} \mathrm{O}+\mathrm{H}_{2}\right)\right\} /$ molecular weight of $\left.3 \mathrm{Co}(\mathrm{OH})_{2}\right\} * 100 \%$

$$
=(38.06 / 3 * 92.95) * 100 \%=13.65 \%
$$




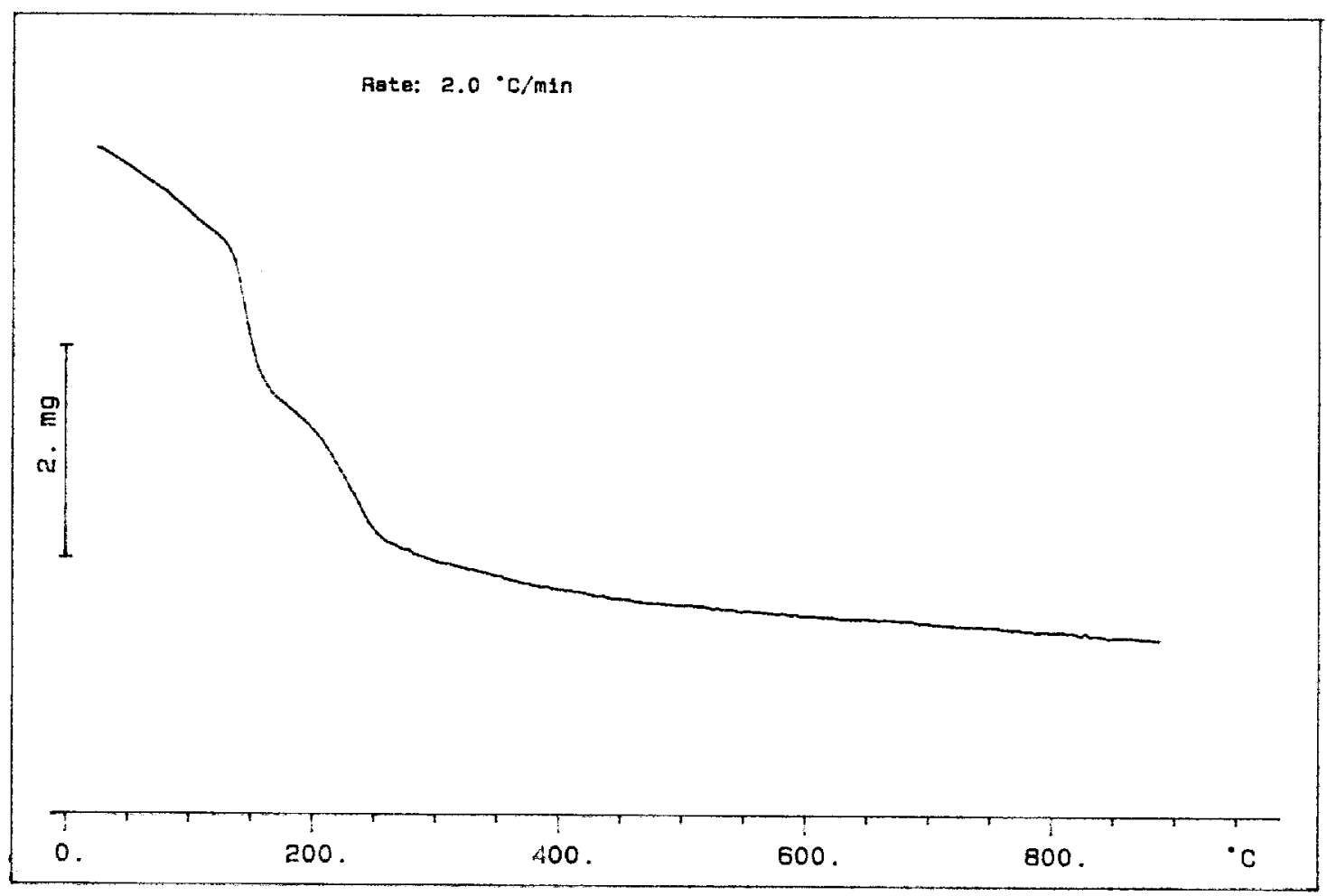

Figure 3.6. Thermogravimetric Analysis of $\mathrm{Co}(\mathrm{OH})_{2}$

\section{3 $\mathrm{Mn}_{5} \mathrm{O}_{8}$ NANOPARTICLES}

\section{a. Literature Review}

14-nm $\mathrm{Mn}_{5} \mathrm{O}_{8}$ was obtained by annealing $\mathrm{Mn}_{3} \mathrm{O}_{4}$ in air at $400^{\circ} \mathrm{C}$ for three hours. In surveying publications on $\mathrm{Mn}_{5} \mathrm{O}_{8}$, heating $\mathrm{Mn}_{3} \mathrm{O}_{4}$ was the only preparation method found. ${ }^{27,28,29,30}$ Our $\mathrm{Mn}_{3} \mathrm{O}_{4}$ sample was prepared from reaction of $\mathrm{Mn}\left(\mathrm{NO}_{3}\right)_{2}$, manganese nitrate, with $\mathrm{NaOH}$. A literature search revealed that manganese salt reacted with base is the standard chemical preparation for $\mathrm{Mn}_{3} \mathrm{O}_{4} \cdot{ }^{31}$ Only one paper, published by Azzoni et al, ${ }^{27}$ was found to explicitly state the particle size of their $\mathrm{Mn}_{5} \mathrm{O}_{8}$ sample 
prepared, which was $21 \mathrm{~nm}$. Magnetic studies conducted on our 14- $\mathrm{nm} \mathrm{Mn}_{5} \mathrm{O}_{8}$ samples were presented in a paper which has been submitted to IEEE Transactions on Magnetics for publication.

\section{b. Synthesis}

An initial attempt to produce $\mathrm{MnO}$ from annealing chemically-prepared $\mathrm{Mn}(\mathrm{OH})_{2}$ failed. A stable sample of $\mathrm{Mn}(\mathrm{OH})_{2}$ could not be prepared from reaction of $\mathrm{Mn}\left(\mathrm{NO}_{3}\right)_{2}$ and $\mathrm{NaOH} . \mathrm{Mn}^{2+}$ partially oxidizes to $\mathrm{Mn}^{3+}$ giving $\mathrm{Mn}_{3} \mathrm{O}_{4}$, hausmannite. ${ }^{31}$

$$
\mathrm{Mn}(\mathrm{OH})_{2}+2 \mathrm{Mn}(\mathrm{OH})_{3} \rightarrow \mathrm{Mn}_{3} \mathrm{O}_{4}+4 \mathrm{H}_{2} \mathrm{O}
$$

$5 \mathrm{~g}$ of $\mathrm{Mn}\left(\mathrm{NO}_{3}\right)_{2}$ were dissolved in $75 \mathrm{~mL}$ of distilled water $(0.1 \mathrm{M}) .125 \mathrm{~mL}$ of $1 \mathrm{M}$ $\mathrm{NaOH}$ were quickly added at room temperature to the nitrate solution. The $\mathrm{pH}$ of the solution was about 13 , while the i.e.p is about 7.0. ${ }^{17}$ The brown precipitate, confirmed through XRD to be pure $\mathrm{Mn}_{3} \mathrm{O}_{4}$, was centrifuged and washed with water. Annealing at $200^{\circ} \mathrm{C}$, the sample remained $\mathrm{Mn}_{3} \mathrm{O}_{4}$. Annealing the fresh $\mathrm{Mn}_{3} \mathrm{O}_{4}$ at $400^{\circ} \mathrm{C}$ gave $\mathrm{Mn}_{5} \mathrm{O}_{8}$. At temperatures of 600,800 , and $1000^{\circ} \mathrm{C}, \mathrm{Mn}_{2} \mathrm{O}_{3}$ formed.

\section{c. Characterization}

XRD confirmed the formation of $14-\mathrm{nm}$ pure $\mathrm{Mn}_{5} \mathrm{O}_{8}$ from annealing chemically prepared $\mathrm{Mn}_{3} \mathrm{O}_{4}$ at $400^{\circ} \mathrm{C}$ in air for three hours (see figure 3.7). 


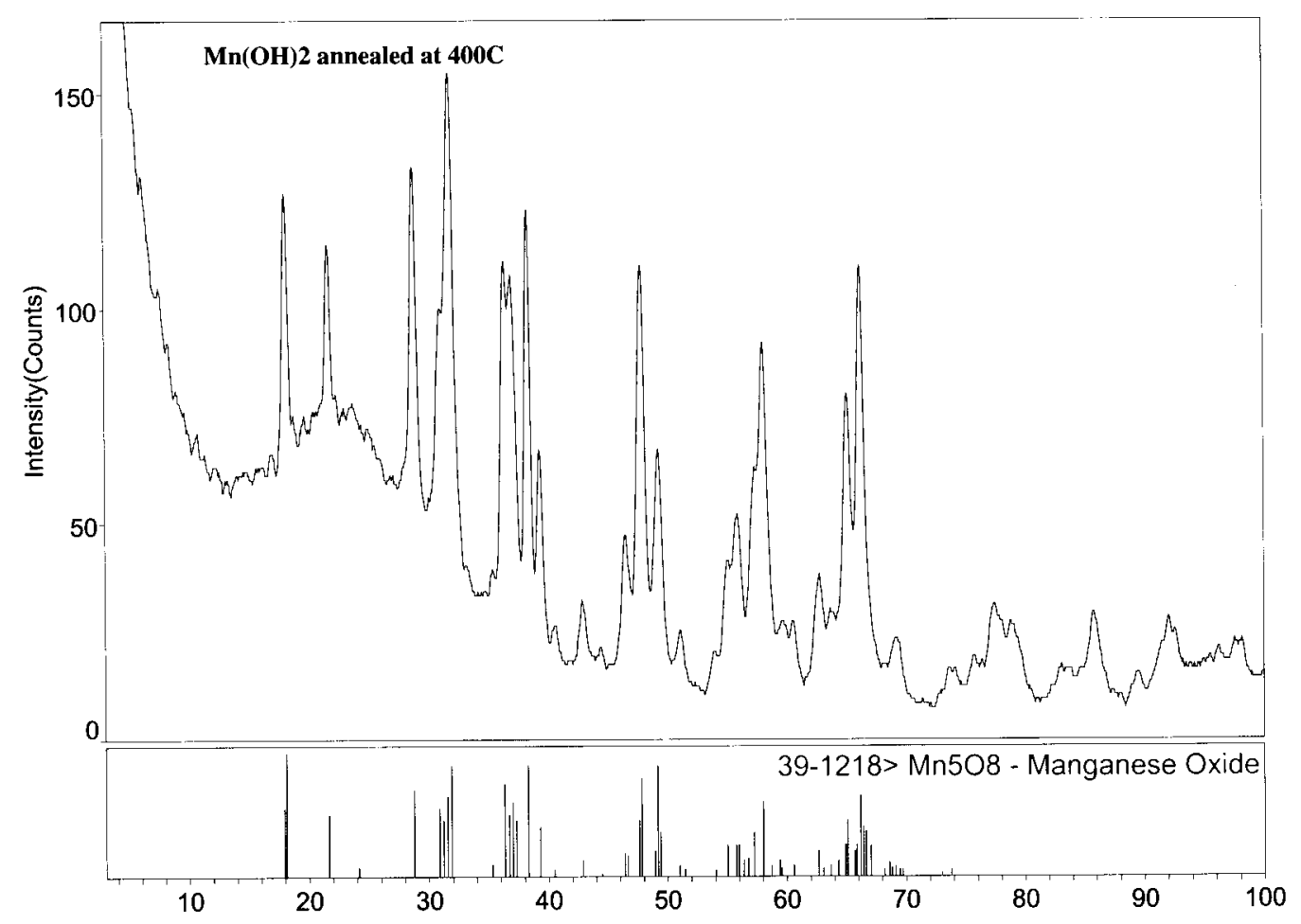

Figure 3.6. X-Ray Diffraction Pattern for $\mathrm{Mn}_{5} \mathrm{O}_{8}$

TGA revealed that $\mathrm{Mn}_{3} \mathrm{O}_{4}$ lost adsorbed water over a temperature range of 25 to $230^{\circ} \mathrm{C}$ (see figure 3.8). $\mathrm{Mn}_{3} \mathrm{O}_{4}$ gained oxygen from 230 to $400^{\circ} \mathrm{C}$.

$$
5 \mathrm{Mn}_{3} \mathrm{O}_{4}+2 \mathrm{O}_{2} \rightarrow 3 \mathrm{Mn}_{5} \mathrm{O}_{8}
$$

Above $400^{\circ} \mathrm{C}, \mathrm{Mn}_{5} \mathrm{O}_{8}$ lost oxygen as it converted to $\mathrm{Mn}_{2} \mathrm{O}_{3}$.

$$
4 \mathrm{Mn}_{5} \mathrm{O}_{8} \rightarrow 10 \mathrm{Mn}_{2} \mathrm{O}_{3}+\mathrm{O}_{2}
$$




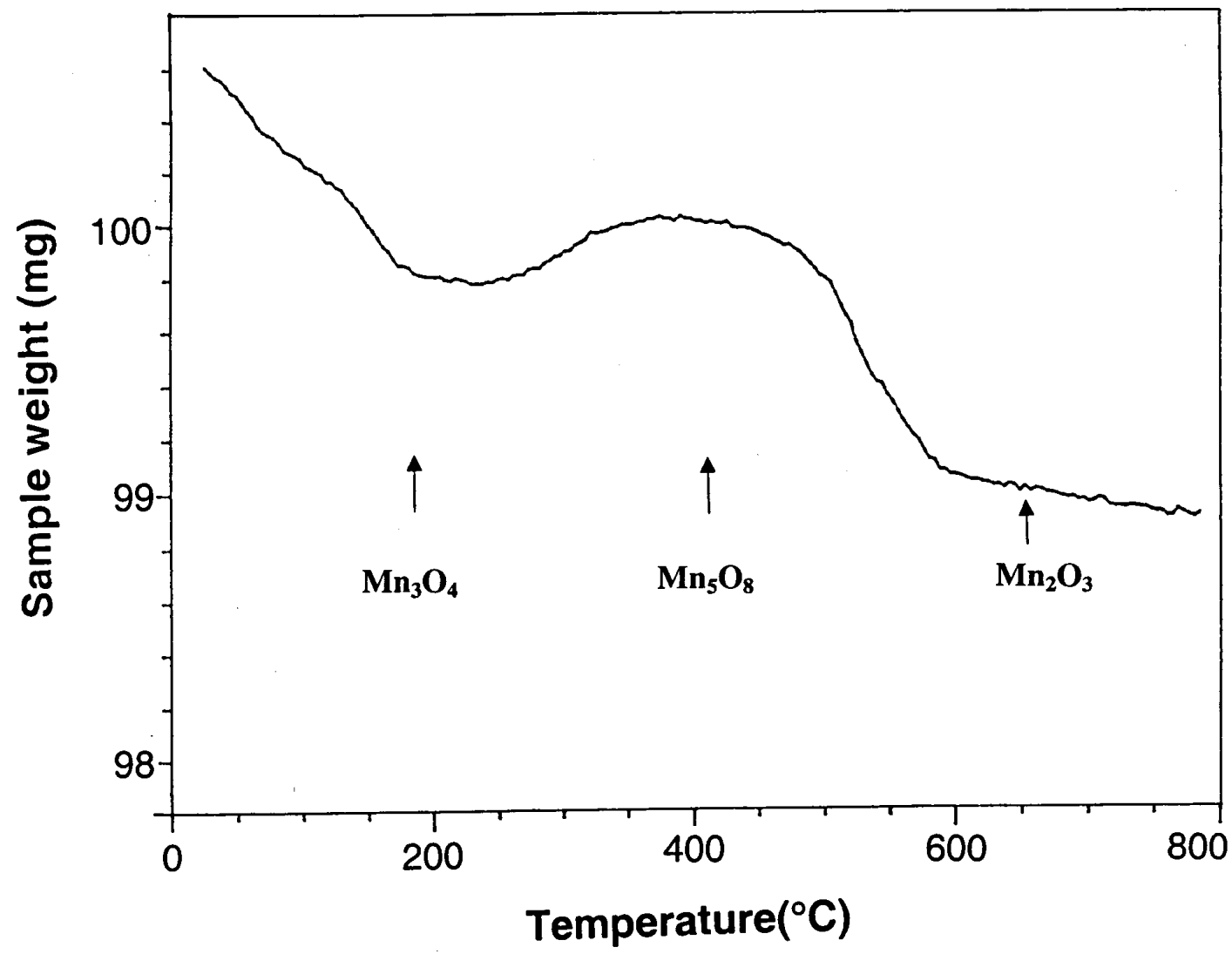

Figure 3.8. Thermogravimetric Analysis of $\mathrm{Mn}_{3} \mathrm{O}_{4}$ 


\section{FUNDAMENTALS OF ELECTROCHEMICAL SYNTHESIS}

$\mathrm{NiO}$ nanoparticles were produced through an electrochemical route modeled after the procedures of Reetz et $\mathrm{al}^{2}$. Reetz produced both Ni and Pd nanoclusters of dimensions between 2.2 and $4.8 \mathrm{~nm}$.

An electrochemical cell was constructed using a nickel plate as anode and a platinum plate as cathode. The electrolytic solution consisted of the solvents acetonitrile (AN) and tetrahydrofuran (THF) in a 4:1 ratio with tetraoctylammonium bromide (TOAB) as the supporting electrolyte and stabilizer. In Reetz's experiment, TOAB effectively stabilized nickel nanoclusters. TOAB has also been shown to stabilize metal oxide nanoparticles, ${ }^{21,32}$ and so it seemed a good candidate as surfactant for the $\mathrm{NiO}$ nanoparticles in our experiment.

The nickel plate is a sacrificing anode, meaning that it donates the nickel atoms to be used in $\mathrm{NiO}$ synthesis. Upon applying a current density, creating an overpotential, $\mathrm{Ni}$ atoms at the anode are oxidized to $\mathrm{Ni}^{2+}$ cations, which tend to leave the bulk metal and enter the solution.

$$
\mathrm{Ni}^{0} \rightarrow \mathrm{Ni}^{2+}+2 \mathrm{e}^{-}
$$

In Reetz's experiment, an argon atmosphere was used to prevent formation of $\mathrm{NiO}$, while in our experiment, an oxygen atmosphere was used to encourage formation of $\mathrm{NiO}$.

$$
2 \mathrm{Ni}^{2+}+\mathrm{O}_{2} \rightarrow 2 \mathrm{NiO}
$$

As $\mathrm{NiO}$ clusters form, TOAB adheres to particle surfaces giving a steric sol (see figure 4.1). The TOAB-stabilized $\mathrm{NiO}$ clusters are insoluble in the AN/THF solution making isolation of the particles possible through centrifugation. 


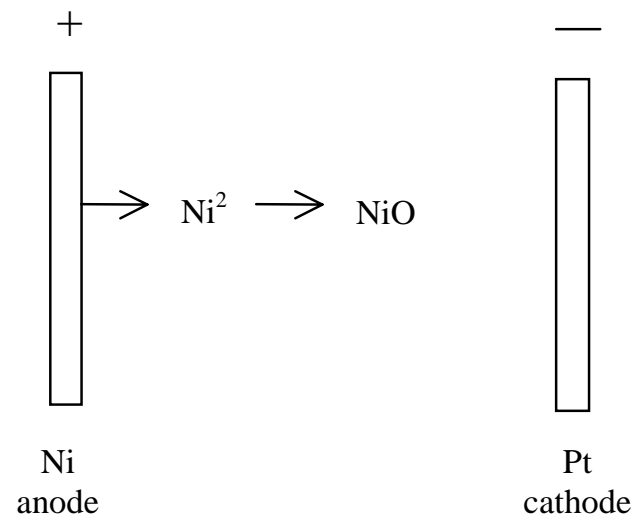

Figure 4.1. Electrochemical Production of NiO Nanoparticles 


\section{ELECTROCHEMICAL PREPARATION OF NiO NANOPARTICLES}

\section{a. Literature Review}

$\mathrm{CuO}^{21}$ and $\mathrm{ZnO}^{32}$ nanoparticles have been prepared through electrochemical methods in the manner of Reetz et al. ${ }^{2}$ However, electrochemical preparation of $\mathrm{NiO}$ nanoparticles was not found in the literature.

\section{b. Synthesis}

The electrolyte solution was prepared by dissolving TOAB in $200 \mathrm{~mL}$ of AN/THF (4:1) to a molarity of 0.1 . The electrolyte, nickel anode, and platinum cathode system was isolated in a closed glass vessel with an oxygen atmosphere. The glass vessel was sealed with a rubber stopper, through which the electrode wires passed, and then placed in an ultrasonic bath to promote mixing. A current density of $0.1 \mathrm{~mA} / \mathrm{cm}^{2}$ was applied for three days over which time the solution turned from clear to cloudy-green. The green solid was separated by centrifugation and washed with THF/AN.

\section{c. Characterization}

XRD confirmed that the product formed was $\mathrm{NiO}$ with particle size $30 \mathrm{~nm}$ (see figure 3.7). The broad background peaks are due to the TOAB coating on the particles. 


\section{RESULTS AND CONCLUSIONS}

$\mathrm{CuO}, \mathrm{Co}_{3} \mathrm{O}_{4}$ and $\mathrm{Mn}_{5} \mathrm{O}_{8}$ nanoparticles were successfully synthesized from metal nitrate precursors using a sol-gel chemical route. Reaction of $\mathrm{Cu}\left(\mathrm{NO}_{3}\right)_{2}$ and $\mathrm{NaOH}$ aqueous solutions produced a $\mathrm{Cu}(\mathrm{OH})_{2}$ gel, which upon annealing for three hours at

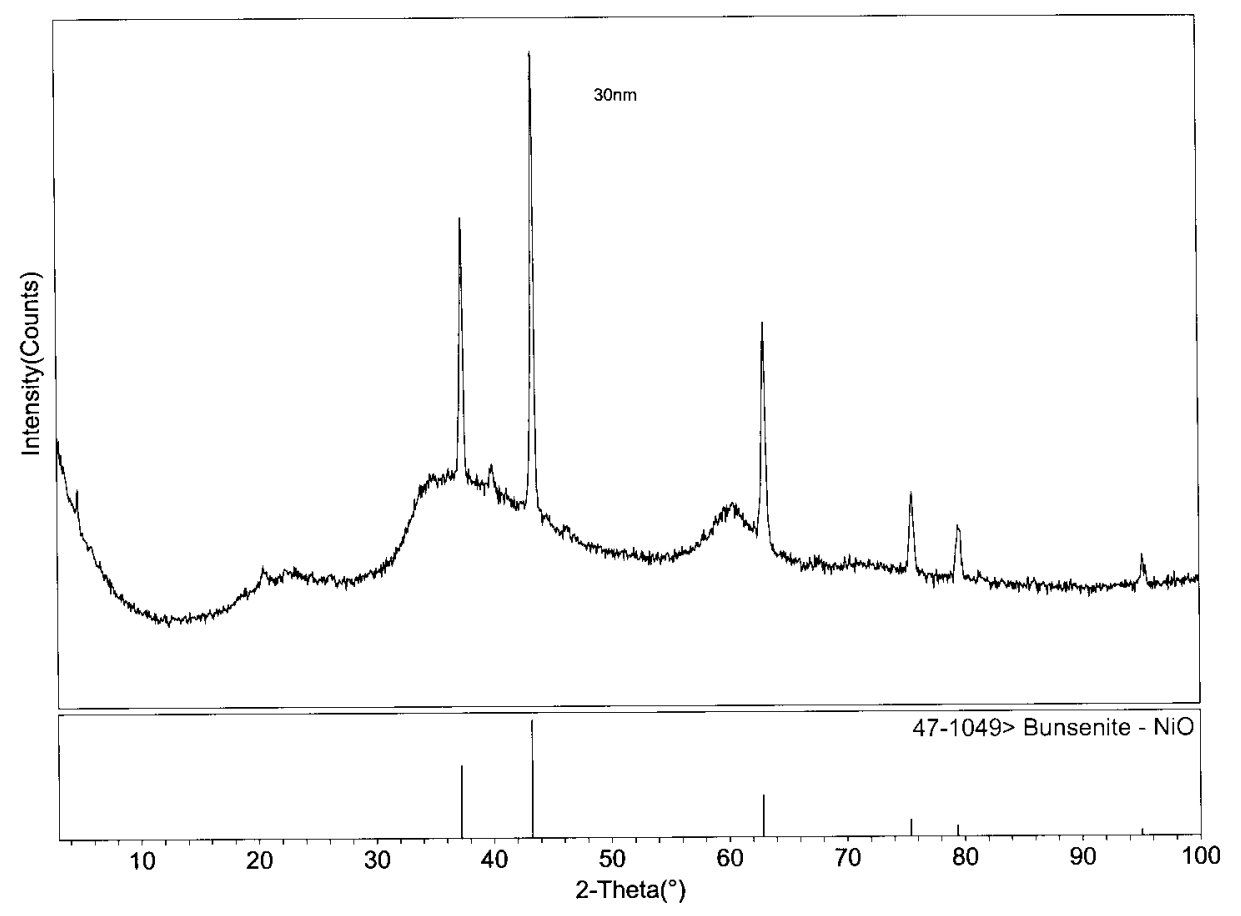

Figure 4.2. X-Ray Diffraction Pattern for NiO

temperatures of $160,200,250,300,400,600,800$ and $1,000^{\circ} \mathrm{C}$ yielded $\mathrm{CuO}$ particles of $6.1,7.8,8.8,11.6,16.4,25.7,34.5$ and $36.0 \mathrm{~nm}$ respectively. These sizes are probably as small as can be expected from solution-chemistry preparation methods. Precipitated particles smaller than about $5 \mathrm{~nm}$ are generally not obtainable because of their tendency to dissolve and reprecipitate onto surfaces of larger particles. 
$\mathrm{Co}_{3} \mathrm{O}_{4}$ nanoparticles of sizes $9.1,10.2,12.1,13.4,17.0,41.9$, and $45.5 \mathrm{~nm}$ were successfully prepared from heating a $\mathrm{Co}(\mathrm{OH})_{2}$ gel, derived from $\mathrm{Co}\left(\mathrm{NO}_{3}\right)_{2}$ and $\mathrm{NaOH}$, at temperatures of $140,150,200,300,400,800$ and $950^{\circ} \mathrm{C}$ respectively.

A pure $14 \mathrm{~nm}$-sample of the metastable $\mathrm{Mn}_{5} \mathrm{O}_{8}$ was prepared from annealing $\mathrm{Mn}_{3} \mathrm{O}_{4}$ for three hours at $400^{\circ} \mathrm{C}$. Reaction of $\mathrm{Mn}\left(\mathrm{NO}_{3}\right)_{2}$ with $\mathrm{NaOH}$ gave the $\mathrm{Mn}_{3} \mathrm{O}_{4}$.

30-nm NiO particles were prepared from an electrochemical method using a nickel metal plate as a sacrificing anode. Generally, a much smaller particle size can be achieved from electrochemistry than from chemical precipitation . Metal oxide particles in a range of 1 to $4 \mathrm{~nm}$ have been prepared electrochemically, ${ }^{21,32}$ so room for improvement in this $\mathrm{NiO}$ preparation method probably exists. Possibly, varying parameters such as current density, distance between electrodes, and surfactant concentrations could result in smaller particle sizes. The sample was washed with an acetonitrile/tetrahydrofuran solution which removed some of the surfactant tetraoctylammonium bromide. Maybe less washing, leaving a thicker coating, would better prevent coagulation resulting in smaller particle sizes. 


\section{REFERENCES}

1. Nalwa, H.S., "Handbook of Nanostructured Materials and Nanotechnology," Vol. I. Synthesis and Processing, Academic Press, San Diego, CA, 2000, p. ix.

2. Reetz, M.T., and Helbig, W., J. Am. Chem. Soc., 116, pp. 7401-7402 (1994).

3. Sapiesko, R.S., and Matijevic, E., Corrosion, 36 (10), pp. $522-530$ (1980).

4. Mazdiyasni, K.S., Lynch, C.T., and Smith, J.S., J. Am. Ceram. Soc., 48 (7), pp. 372-375 (1965).

5. Pierre, A.C., "Introduction to Sol-Gel Processing," Kluwer Academic Publishers, Norwell, MA, 1998, pp. 2-17, 26, 27, 92-95, 140, 141, 182-185, 232-245, 278$287,300-331$.

6. Lee, S.H., Her, Y.S., and Matijevic, E., J. Colloid Interface Sci., 186, pp. 193-202 (1997).

7. Sugimoto, T., and Matijevic, E., J. Inorg. Nuclear Chem., 41 (2), pp. 165-172 (1978).

8. Makhlouf, S.A., Parker, F.T., Spada F.E., and Berkowitz, A.E., J. Appl. Phys., 81 (8), pp. 5561-5563 (1997).

9. Matijevic, E., and Scheiner, P., J. Colloid Interface Sci., 63 (3), pp. 509-524 (1977).

10. Sugimoto, T., and Matijevic, E., J. Colloid Interface Sci., 74 (1), pp. 227-243 (1980).

11. Matijevic, E., Budnik, M., and Meites, L., J. Colloid Interface Sci., 61 (2), pp. 302-311 (1977). 
12. Blesa, M.A., Maroto, A.J.G., Passaggic, S.I., Figliolia, N.E., and Rigotti, G., J. Mater. Sci., 20, pp. 4601-4609 (1985).

13. Spanhel, L., and Anderson, M.A., J. Am. Chem. Soc., 113, pp. 2826-2833 (1991).

14. Baes, C.F., and Mesmer, R.E., "Hydrolysis of Cations," John Wiley \& Sons, New York, N.Y., 1976, pp. 5, 219-226, 238-247, 267-275.

15. Vold, M.J., and Vold, R.D., "Colloid Chemistry: The Science of Large Molecules, Small Particles, and Surfaces,” Reinhold Publishing Corp., New York, N.Y., 1964, pp. 1-36.

16. Brinker, C.J., and Scherer, G.W., "Sol-Gel Science: The Physics and Chemistry of Sol-Gel Processing," Academic Press, San Diego, CA, 1990, pp. 240, 244, 360, 362, 384, 402, 413, 414, 424, 444, 445, 453, 464, 501, 506, 562.

17. Parks, G.A., Chem. Rev., 65, pp. 177-198 (1965).

18. Hunter, R.J., "Zeta Potential in Colloid Science,” Academic Press, New York, N.Y., 1981, pp. 228-229, 278-279.

19. Kumar, R.V., Diamant, Y., and Gedanken, A., Chem. Mater., 12, pp. 2301-2305 (2000).

20. Brookshier, M.A., Chusuei, C.C., and Goodman, D.W., Langmuir, 15 (6), pp. 2043-2046 (1999).

21. Borgohain, K., Singh, J.B., Rao, M.V.R., Shripathi, T., and Mahamuni, S., Phys. Rev. B, 61 (16), pp. $11093-11096$ (2000).

22. Kratohvil, S., and Matijevic, E., J. Mater. Res., 6 (6), pp. 766-777 (1991).

23. Ibrahim, M.M., Zhao, J., and Seehra, M.S., J. Mater. Res., 7 (7), pp. 1856-1860 (1992). 
24. Palker, V.R., Ayyub, P., Chattopadhyay, S., and Multani, M., Phys. Rev. B, 53 (5), pp. 2167-2170 (1996).

25. Ramamurthy, P., and Secco, E., Can. J. Chem., 47, pp. 3915-3918 (1969).

26. Verelst, M., Ely, T.O., Amiens, C., Snoeck, E., Lecante, P., Mosset, A., Respaud, M., Broto, J.M., and Chaudret, B., Chem. Mater., 11, pp. 2702-2708 (1999).

27. Azzoni, C.B., Mozzati, M.C., Galinetto, P., Paleari, A., Massarotti, V., Capsoni, D., and Bini, M., Solid State Commun., 112, pp. 375-378 (1999).

28. Wolska, E., and Kaczmarek, J., Solid State Phenom., 39-40, pp. 153-156 (1994).

29. Fritsch, S., Sarrias, J., Rousset, A., and Kulkarni, G.U., Mater. Res. Bull., 33 (8), pp. 1185-1194 (1998).

30. Sugawara, M., Ohno, M., and Matsuki, K., Chem. Lett., 8, pp. 1465-1468 (1991).

31. Moon, J., Awano, M., Takagi, H., and Fujishiro, Y., J. Mater. Res., 14 (12), pp. 4594-4601 (1999).

32. Mahamuni, S., Borgohain, K., and, Bendre, B.S., J. Appl. Phys., 85 (5), pp. 28612865 (1999). 


\section{VITA}

$\begin{array}{ll}\text { Name: } & \text { Heidi Jo Magnone } \\ \text { Parents: } & \text { Gary B. Davenport } \\ & \text { Donna S. Davenport } \\ \text { Husband: } & \text { James J. Magnone, Jr. } \\ \text { Birthplace: } & \text { Martin's Ferry, Ohio } \\ \text { Date of Birth: } & \text { July 18, 1970 }\end{array}$

Schools Attended: St. Clairsville High School, St. Clairsville, OH $1984-1988$

Ohio University Eastern, St. Clairsville, OH 1988 - 1990

Ohio University, Athens, OH $1990-1993$

Wheeling Jesuit University, Wheeling, Wheeling, WV 1993 - 1995

Degrees Received: $\quad$ B.S., Physics, Wheeling Jesuit University 1995 